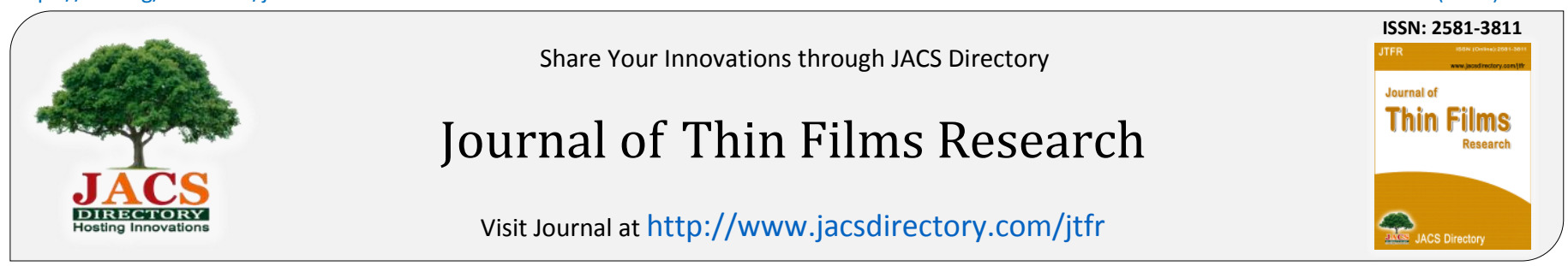

\title{
Theoretical and Experimental Characterization of Efficient Anti-Dust Coatings under Desert Conditions
}

\author{
R.J. Isaifan ${ }^{1,2 *}$, D. Johnson ${ }^{1,3}$, S. Mansour ${ }^{1}$, A. Samara ${ }^{1}$, W. Suwaileh ${ }^{1}$, K. Kakosimos ${ }^{4}$ \\ ${ }^{1}$ Qatar Environment and Energy Research Institute, Hamad Bin Khalifa University, Qatar Foundation, P.O. Box 5825, Doha, Qatar. \\ ${ }^{2}$ College of Science and Engineering, Hamad Bin Khalifa University, Qatar Foundation, P.O. Box 5825, Doha, Qatar. \\ ${ }^{3}$ Centre for Water Advanced Technologies and Environmental Research (CWATER), College of Engineering, Swansea University, UK. \\ ${ }^{4}$ Chemical Engineering Department, Texas A\&M University at Qatar, Doha, Qatar.
}

\section{ART I C L E DETAILS}

Article history:

Received 16 April 2018

Accepted 26 April 2018

Available online 08 May 2018

Keywords:

Titanium Dioxide

Self-Cleaning

Adsorptive Self-Assembly

Transmission Loss

\begin{abstract}
A B S T R A C T
Transparent titania coatings have self-cleaning and anti-reflection properties (AR) that are of great importance in optical and solar applications. In this work, an efficient and easy to scale up adsorptive self-assembly process is used to coat glass substrates with two $\mathrm{TiO}_{2}$ nanocolloids (TC- 1 and $\mathrm{TC}-2$ ) prepared via polyol method. TEM images of the nanoparticles show an average particle size of 2.6 and $167.7 \mathrm{~nm}$ of TC-1 and TC-2, respectively. The theoretical values for the coating thickness as well as for the antireflective index were compared with the experimental values obtained via elipsometer measurements. The self-cleaning properties were investigated by optical microscopy, atomic force microscopy, contact angle, surface tension and UV-vis spectroscopy. The optical images show 56\% reduction of dust deposition rate with lower adhesion force over the best performing coated surfaces TC-1 compared with bare glass substrates and TC- 2 after 7 days of soiling.
\end{abstract}

\section{Introduction}

Titanium dioxide $\left(\mathrm{TiO}_{2}\right)$ is one of the most widely investigated photocatalytic materials that can be used in the decomposition of volatile organic compounds, advanced oxidation processes for wastewater and bactericidal treatments, window glass self-cleaning for green intelligent buildings, dye-sensitized solar cells, solid-state semiconductor metaloxide solar cells and self-cleaning glass for photovoltaic devices [1-3]. $\mathrm{TiO}_{2}$ decomposes the organic pollutants settling on its surface when irradiated with UV light turning the surface to be hydrophilic [4]. Hydrophilic $\mathrm{TiO}_{2}$ thin films have the characteristics of spreading water out on its surface, thus carrying dust particles away while flowing down the surface. Therefore, the photocatalytic characteristics combined with the hydrophilic properties of $\mathrm{TiO}_{2}$ makes it an excellent self-cleaning surface that attracts worldwide attention for many applications to save time and cost with regular cleaning methods [5].

Several coating processes have been proposed to prepare uniform $\mathrm{TiO}_{2}$ coatings. Liu et al. [6] prepared titanium thin film by sol gel method. Abdulraheem et al. [7] successfully synthesized $\mathrm{TiO}_{2}$ thin films by electron beam assisted physical vapor deposition. Da Silva et al. [8] used microwave heating to prepare thin $\mathrm{TiO}_{2}$ films. Nevertheless, low-cost controllable solution-based processes for preparation of $\mathrm{TiO}_{2}$ thin films are highly desirable. Recently, Xi et al. [5] proposed an efficient and easy to scale up coating method for uniform and homogeneous $\mathrm{TiO}_{2}$ thin films for self-cleaning applications. Their method relies on developing a solution-based adsorptive self-assembly approach to fabricate anatase $\mathrm{TiO}_{2}$ thin films on glass substrates. They were able to tune the number of process cycles to increase the film thickness into the desired value. Moreover, the as-prepared nanostructured $\mathrm{TiO}_{2}$ thin films on glass substrate did not cause deterioration of the optical transmission of glass; instead, they improved optical performance of commercial solar cells over a wide range of incident angles of light which is a very critical factor for self-cleaning of optical devices and solar panels.

In this work, we report on the use of two $\mathrm{TiO}_{2}$ nanocolloids prepared via polyol method starting from two different titanium precursor salts and characterized by transmission electron microscopy (TEM). The coating

films were deposited via adsorptive self-assembly method [5] and characterized by scanning electron microscopy (SEM), ellipsometery, atomic force microscopy (AFM), optical microscope, UV-vis, contact angle and surface tension measurements. Moreover, the effect of soiling on the transmission properties of the coated glass was studied for self-cleaning application of solar panels under desert conditions.

\section{Experimental Methods}

\section{$2.1 \mathrm{TiO}_{2}$ Nanocolloids Synthesis}

Two $\mathrm{TiO}_{2}$ nanocolloids were prepared by polyol method as described in details in [9-11]. Starting with about $2.7 \mathrm{~g}$ of each of two precursor salts: Titanium (IV) oxysulfate $\left(\mathrm{TiOSO}_{4}\right.$, Sigma-Aldrich $99 \%$ ) for coating 1 (TC1) and titanium isopropoxide $\left(\mathrm{Ti}\left(\mathrm{OCH}\left(\mathrm{CH}_{3}\right)_{3}\right)_{4}\right.$, (Sigma Aldrich, 95\%) for coating 2 (TC-2) that were measured and introduced into a three-neck flask and stirred for $30 \mathrm{~min}$ to dissolve in tetraethyleneglycol (TEG) from (Sigma-Aldrich, $\geq 99 \%$ ) at room temperature. To control the particle size of the synthesized nanoparticles, $2.9 \mathrm{~g}$ of sodium hydroxide pellets were dissolved in $5 \mathrm{~mL}$ of deionized water and the solution was gradually added to the mixture using a syringe. The mixture was mechanically stirred and heated at a rate of $6{ }^{\circ} \mathrm{C} \mathrm{min}-1$ from room temperature to $165{ }^{\circ} \mathrm{C}$ under reflux for 3 hours. At this stage, $\mathrm{TiO}_{2}$ nano-colloids were synthesized.

\subsection{Preparation of Coating Films}

Borosilicate plate glass slides (Chemglass CG-1904-36) of $25 \mathrm{~mm} \times 10$ $\mathrm{mm} \times 2 \mathrm{~mm}$ (width $\mathrm{x}$ length $\mathrm{x}$ thickness) were used as work pieces. Before deposition, the glass substrate samples were cleaned with ethanol and rinsed with deionized water. Then, each substrate sample was soaked in Piranha solution which was prepared by mixing sulfuric acid $\left(\mathrm{H}_{2} \mathrm{SO}_{4}\right.$ concentration of 5-6\%, Merck) with hydrogen peroxide $\left(\mathrm{H}_{2} \mathrm{O}_{2}\right.$, concentration of $30 \%$, Merck) in a volume ratio of 2:1 for 30 minutes. Later, the samples were thoroughly rinsed with deionized water and left to dry in the oven at $70{ }^{\circ} \mathrm{C}$ for another 30 minutes. The dried glasses were then dipped in nanocolloids for 2 hours (Fig. 1) at $20^{\circ} \mathrm{C}$ and at a relative humidity of around $30 \%$. The samples were then placed in an oven (Thermolyne, Thermo Scientific) at a temperature of $400{ }^{\circ} \mathrm{C}$ under air for 2 hours following the procedure depicted [5]. The prepared sample had a replicate of 3 to assure reproducibility of the experimental results (Fig. 1). 


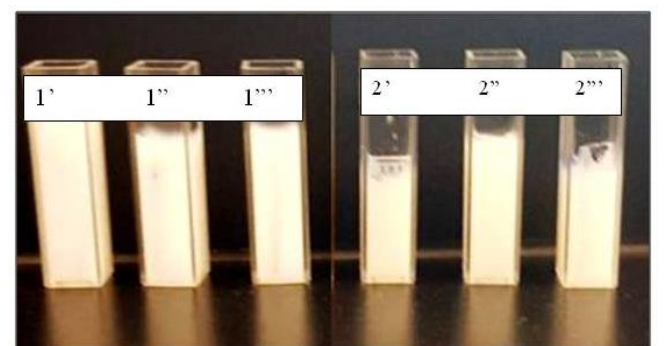

Fig. 1 Dipping glass substrate samples in $\mathrm{TiO}_{2}-1$ and $\mathrm{TiO}_{2}-2$ for soaking time of $2 \mathrm{~h}$

\subsection{Characterization Techniques}

The transmission electron microscopy (TEM) analysis was carried out using FEI TALOS X operated at $200 \mathrm{kV}$. The TEM specimens were prepared by sonicating the as-prepared $\mathrm{TiO}_{2}$ catalyst powder in ethanol. One drop of the solution was then placed onto a 200 mesh TEM copper grid coated with a lacey carbon support film (Ted Pella) and dried in air. We used Image J software for the determination of particle size distribution.

Scanning electron microscopy (SEM) images were obtained using SEM Model JCM-6000PLUS NeoScope to observe the morphology of coating layers of $\mathrm{TiO}_{2}$ in different positions of the glass cross sections. SEM/SEI topographical images were obtained on the glass samples with magnification of 500X and 200X and resolution of $256 \mathrm{X} 192$ pixels at an accelerating voltage $10 \mathrm{kV}$, an energy range $0-20 \mathrm{KeV}$ and high vacuum mode.

AFM measurements were carried out using a Dimension Icon model AFM with NanoScope V Controller (Bruker AXS, USA). Roughness values were obtained from images obtained with NSG30 silicon tapping mode probes (NT-MDT, Russia) operating in PeakForce mode. All force interaction measurements were made in ambient conditions using NP-O type silicon nitride tip-less contact mode probes (Bruker, USA). Single dust particles were mounted close to the apex of the probe using careful control of the AFM stage. Firstly, a thin smear of slow curing epoxy resin was placed on the end of a cleaned glass microscope slide. A small amount of dust particles were placed elsewhere on the same slide. Excess particles were removed using a stream of nitrogen to leave only individual particles directly attached to the surface. The tip of the AFM cantilever was first placed into the edge of the epoxy resin, taking care to only remove a thin layer of adhesive. Next an individual particle separated from other particles of suitable size and regular shape was identified. The probe tip was then brought into and out of contact with the particle. Colloidal probes created in this manner were left overnight to allow the adhesive to fully cure. For each set of measurements 100 particle - surface interaction events were recorded, with each measurement being part of a $10 \times 10$ array separated by $1 \mu \mathrm{m}$ in the $\mathrm{x}$ and $\mathrm{y}$ directions, to ensure that all measurements were taken from different locations on the sample surface. From features of the force-distance curves, the adhesion force for each interaction was measured and mean values for each surface of interest were calculated $[12,13]$.

Transmittance spectra of the coated samples were recorded in the 200$1000 \mathrm{~nm}$ range using a Jenway-67 Series spectrophotometer.

Optical analysis of the coated surfaces was performed using Olympus (IX73) optical microscope. The objective lens of 40X magnification was used.

The surface wettability and surface tension were evaluated by measuring the contact angle and surface tension of deionized water droplets deposited on the film surface under ambient conditions using a rame-hart goniometer with three replicates. The acquired images have been elaborated with Drop Image software to obtain the average contact angles.

The thin film thickness and refractive index for all samples were measured using J.A. Woollam WVASE Ellipsometer. Each sample was tested using 2 ellipsometer angles $\left(65^{\circ}\right.$ and $\left.70^{\circ}\right)$, and light wavelength scan between 300 and $1000 \mathrm{~nm}$. The ellipsometer measures the changes in the light polarization state and generates a graph of the changes in ellipsometric angles $(\Delta, \Psi)$ as a function of wavelength. In the analyses of the ellipsometric data, the samples were treated as composed i.e. a $\mathrm{TiO}_{2}$ thin film on a thick $\mathrm{SiO}_{2}$ substrate. For simplicity, a basic Cauchy model for transparent films was used to fit the data, and the average thickness and refractive index of the $\mathrm{TiO}_{2}$ layer were calculated numerically from the $\Psi$ and $\Delta$ functions. The results of the ellipsometric measurement were in close agreement with the theoretical values obtained by Eq.(1) [14]:

$$
\mathrm{d}=\frac{f}{2 D_{n} \sqrt{n^{2}-\sin ^{2} \theta}}
$$

where; $d$ : film thickness $(\mu \mathrm{m})$; $\mathrm{f}$ : number of fringes in wave number region used; n: refractive index of the glass substrate; $\theta$ : angle of incidence and $\mathrm{D}_{\mathrm{n}}$ : wavenumber region used $\left(\mathrm{v}_{1}-\mathrm{v}_{2} ; \mathrm{cm}^{-1}\right)$

https://doi.org/10.30799/jtfr.013.18020101
Eq.(1) is based on the theory that in the case of a thin film deposited on the surface of another material; both the top and bottom surfaces of the film reflect light, with the total amount reflected being the sum of these two reflections. Furthermore, these two reflections may add together constructively or destructively depending on their phase relationship. This phenomenon is due to the wave-like nature of light, with the phase relationship determined by the difference in optical path lengths of the two reflections. The resulting interference pattern (interference fringes) can be used to determine the thickness of the film, assuming that refractive index and angle of incidence are both known [14].

To calculate the refractive index, another theoretical method based on the case when a transparent homogeneous film of uniform thickness (d) and refractive index (n) is bounded on either side by two semi-infinite non absorbing layers of refractive indices $n_{0}$ and $n_{2}$, such that $n_{0}<n>n_{2}$ or $n_{0}$ $>\mathrm{n}<\mathrm{n}_{2}$, then for the minimum transmittance $\left(\mathrm{T}_{\min }\right)[15]$ :

$$
n d=\frac{1}{4}(2 m+1) \lambda
$$

and,

$$
T_{\min }=\left[\frac{\left(4 n_{o} n^{2} n_{2}\right)}{\left(n_{o} n_{2}+n^{2}\right)^{2}}\right]
$$

where $m=(0,1,2,3, \ldots)$ is the order of the mimina and $\lambda$ is wavelength at which $\mathrm{T}_{\min }$ occurred.

In the case of $\mathrm{TiO}_{2}$ films deposited on glass substrate, $\mathrm{n}_{\mathrm{o}}<\mathrm{n}>\mathrm{n}_{2}$ applies since $n_{0}=1$ for air, $n=2.52$ for $\mathrm{TiO}_{2}$ anatase [16] and $\mathrm{n}_{2}=1.515$ for glass.

Rearranging Eq.(3) to estimate the refractive index (n) at the minimum measured transmittance $\left(\mathrm{T}_{\min }\right)$ :

$$
\mathrm{n}=\left[\sqrt{\left(n_{o} n_{2}\right)}\left(\frac{1+\sqrt{1-T_{\min }}}{\sqrt{T_{\min }}}\right)\right]
$$

The film thickness values obtained by the two theoretical method and the measured vales by the ellipsometer were compared with the ideal optical film thickness obtained from the following equation [16]

$$
\text { Ideal optical film thickness }=\frac{\lambda}{4}
$$

where $\lambda$ is the wavenumber at which transmittance was maximum.

The ideal refractive index was obtained by Eq.(6) [16], and the values were compared with the measured ones from the ellipsometer:

$$
n=\sqrt{\left(n_{o} n_{2}\right)}
$$

The application of the theoretical equations was based on the collected UV-vis data in the range of 400-800 as recommended $[15,16]$.

\section{Results and Discussion}

Fig. 2 shows bright field TEM of the $\mathrm{TiO}_{2}$ colloidal particles where the black localized features corresponding to the $\mathrm{TiO}_{2}$ nanoparticles. Typically, the nanopartciles sizes were found to be uniform and spherical in shape in TC-1, with the presence of few non-uniform particles resulting most probably from agglomeration process. The size of the nano-particles ranges from 2 to $5 \mathrm{~nm}$ with an average particle size estimated to be around $2.61 \mathrm{~nm}$. However, $\mathrm{TiO}_{2}$ nanoparticles in $\mathrm{TC}-2$ were much larger (average particle size is around $167 \mathrm{~nm}$ ) with hexagonal particle shape.
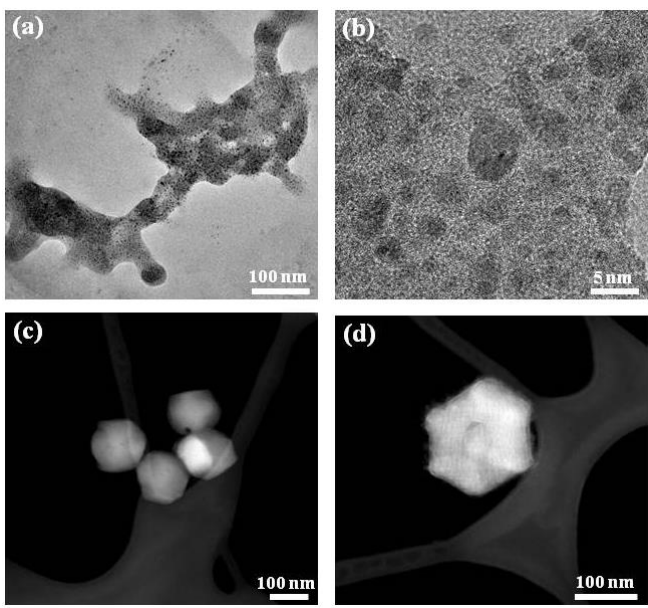

Fig. 2 TEM micrographs of $\mathrm{TiO}_{2}-1$ (a) and (b), and $\mathrm{TiO}_{2}-2$ (c) and (d) 
Film thickness values obtained via theoretical methods utilizing UV-vis spectra and the measured film thickness values using ellipsometer of the two coating films are summarized in Table 1 . The calculations were performed considering a refractive index of glass substrate $n=1.515$, angle of incidence $\theta=90^{\circ}$, and counting the fringes in the UV-vis spectra in the range between $\mathrm{v}_{1}=800 \mathrm{~cm}^{-1}$ and $\mathrm{v}_{2}=400 \mathrm{~cm}^{-1}$.

Table 1 Theoretical and measured film thickness for $\mathrm{TiO}_{2}$ coatings

\begin{tabular}{|c|c|c|}
\hline Coating & Film thickness (nm)a & Film thickness $(\mathrm{nm})^{\mathrm{b}}$ \\
\hline TC-1 & 77.5 & 76.2 \\
\hline TC-2 & 72.9 & 64.7 \\
\hline
\end{tabular}

aFrom Eq.(1) based on single face coating

bSingle face coating measured by ellipsometer

The results in our study are in good agreement with the film thickness obtained by Xi et al. [5] when they first proposed this technique for selfcleaning applications measured after one cycle of coating and heating procedure. The thickness they obtained for one process cycle is $70 \pm 4 \mathrm{~nm}$. Single process cycle as per the authors is the dipping of the substrate in the colloids for a soaking period of $2 \mathrm{~h}$ and the subsequent heating at $400^{\circ} \mathrm{C}$ for another $2 \mathrm{~h}$. If another cycle is required to form another layer, the coated sample should be dipped in the colloids for another $2 \mathrm{~h}$ and heated in air for $2 \mathrm{~h}$, and so on. As mentioned earlier, this technique is simple and does not involve any sophisticated apparatus. Indeed, Xi et al. [5] have reported that they could successfully scale up the coating films on larger areas ( $125 \mathrm{~mm} \times 125 \mathrm{~cm} \times 2 \mathrm{~mm})$.

Fig. 3 shows optical images taken by the optical microscope using $40 \mathrm{X}$ magnification object lens after soiling for 7 days. The images show that titania coating (TC-1) deposited using $\mathrm{TiO}_{2}-1$ colloidal nanoparticles show less accumulation of dust particles compared with uncoated glass UC and TC-2 after the samples were left for soiling for one week.
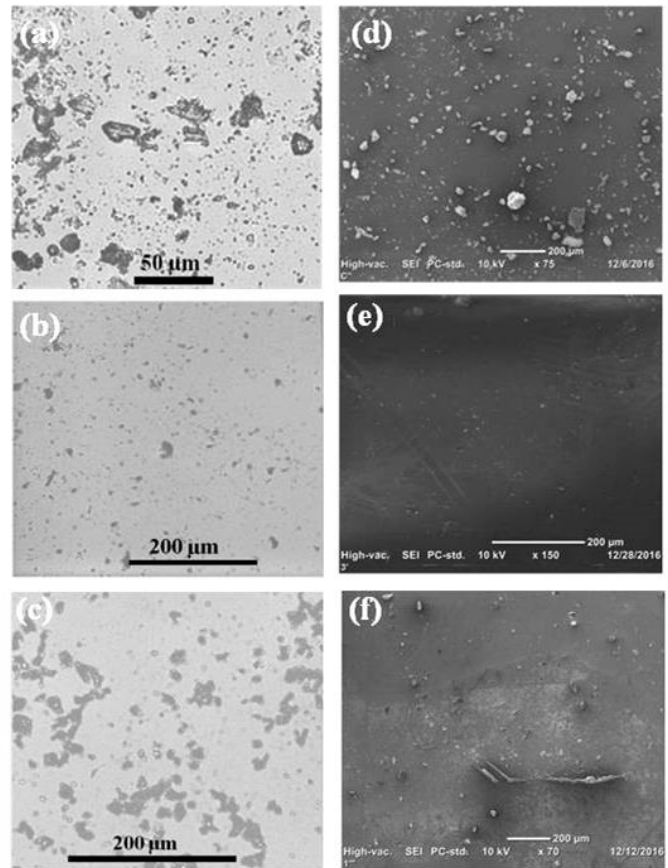

Fig. 3 Optical images of glass substrate samples (a) not coated, (b) coated with TC-1, (c) coated with TC-2 and SEM images of (d) not coated, (e) coated with TC-1 and (f) coated with TC-2 after soiling for 7 days in Doha for all samples

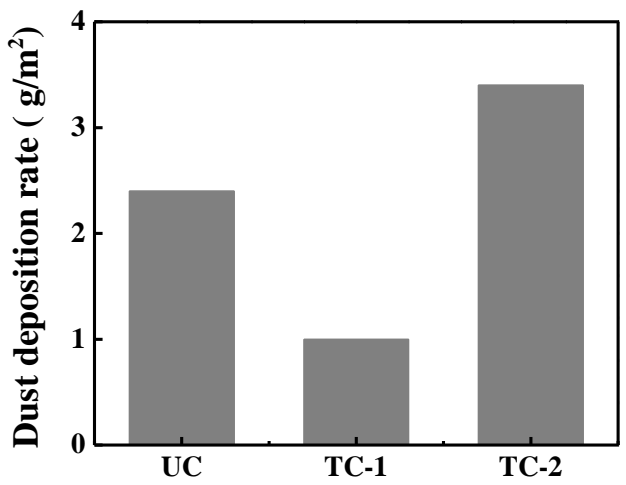

Fig. 4 Rate of dust deposition for seven days on uncoated sample (UC) and coated samples TC- 1 and TC-2

https://doi.org/10.30799/jtfr.013.18020101
Moreover, Fig. 4 shows the rate of dust deposition per surface area of glass substrate after soiling for one week. The values show a significant decrease of dust deposition rate on TC- 1 compared with TC- 2 and the uncoated substrate.

To investigate the effect of coating on the optical transmission of the glass substrate, UV-Vis spectra was collected for the coated and uncoated glass surfaces after soiling for 7 days. The Spectra are shown in Fig. 5. The transmission of the clean glass had a maximum value of $91.75 \%$ in the range of values $(90-92 \%)$ as reported in many studies [16, 17]. To investigate the effect of coating in mitigating the dust accumulation onto the coated substrates, the samples were left at the solar test facility located in Doha/ The State of Qatar, for 7 days. It is shown that the coated sample TC- 1 shows an average transmission reduction of only $6 \%$ in the visible region (400- $800 \mathrm{~nm}$ ) compared with clean uncoated surface. The slight loss in optical transmission in the visible range has been reported in the literature to be due to the increased surface roughness [18].

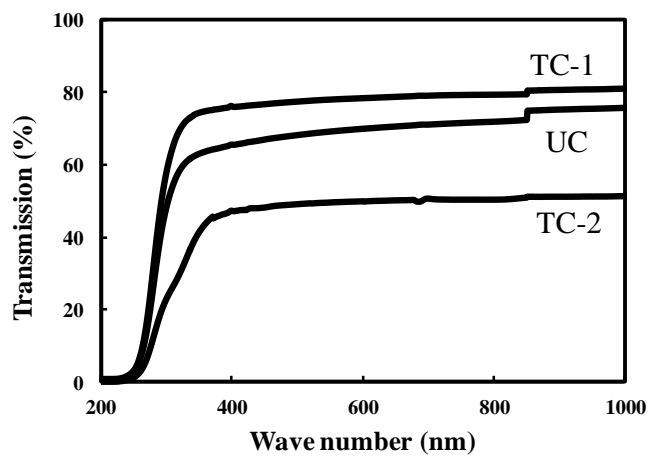

Fig. 5 UV-Vis spectra of the samples after soiling for 7 days

The antireflection properties which depend on the interference of the reflected light from air-coating and coating substrate interfaces were examined. For an ideal homogeneous single coating which has a refractive index value between that of air and the substrate, the antireflection coating should satisfy the following conditions: the thickness of the coating should be $\lambda / 4$, where $\lambda$ is the wavelength of the incident light; and $n_{c}=\left(n_{a}\right.$ $\left.\mathrm{x} \mathrm{n}_{\mathrm{s}}\right)^{0.5}$, where $\mathrm{n}_{\mathrm{c}}, \mathrm{n}_{\mathrm{a}}$, and $\mathrm{n}_{\mathrm{s}}$ are the refractive indices of the coating, air, and substrate, respectively [19]. Taking into consideration that $n_{a}=1$ for air, $n_{s}$ is 1.52 for glass substrate, $\mathrm{n}_{\mathrm{c}}$ must be 1.23 to achieve zero reflection. Since this value is lower than that of any homogeneous dielectric material, antireflective coatings always adopt 2- or 3-dimensional porous structures to meet the requirement for very low average refractive indece $[16,19]$. The measured and theoretical refractive index for TC- 1 and TC- 2 are shown in Table 2. It can be seen that TC-1 has a refractive index of 1.889 compared with 2.785 for TC-2. This low refractive index of TC-1 is closer to the ideal optical refractive index obtained for the case of glass substrate in air as per Eq.(6). Hence TC-1 has improved anti-reflection properties which are critical for PV applications [16]

Table 2 Theoretical and measured refractive indices for $\mathrm{TiO}_{2}$ coatings

\begin{tabular}{llll}
\hline Coating & Refractive index $^{\mathrm{a}}$ & Refractive index $^{\mathrm{b}}$ & Ideal optical refractive index $^{\mathrm{c}}$ \\
\hline TC-1 & 1.889 & 1.51 & \multirow{2}{*}{1.23} \\
TC-2 & 2.785 & 1.82 & \\
\hline a from Eq.(4); ${ }^{\mathrm{b}}$ measured by ellipsometer; cfrom Eq.(6)
\end{tabular}

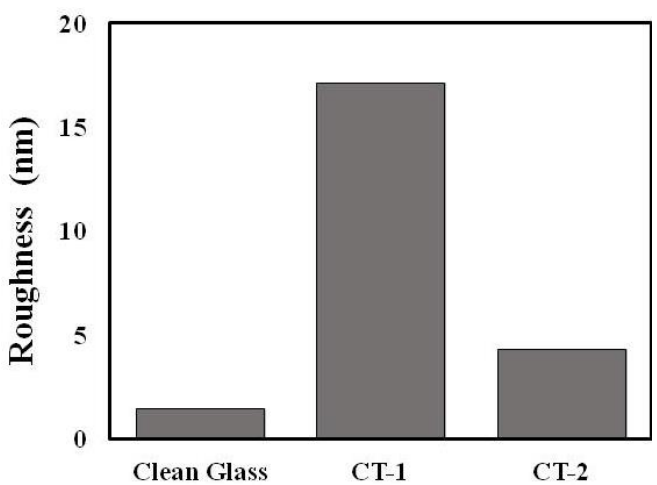

Fig. 6 Surface roughness of clean uncoated, and coated glass substrates (TC-1 and TC-2)

To further investigate on the properties of the coated samples, the surface roughness was measured via AFM and the results are shown in Fig. 6 . Roughness root mean squared (RMS) values were calculated from 3 
images of 5 x $5 \mu \mathrm{m}$ using instrument software. The surface roughness has a critical impact on the adhesion force between particles and substrates. In general, as the surface roughness increases, the adhesion force decreases. This trend has been reported in several studies [20-23]. The exact effect of roughness can be studied based upon its impact on the two main forces that control the mechanism of soiling: Van der Waals and the capillary force. In the case of the Van der Waals force, it is a short range force where the increase in surface roughness results in a smaller contact area between the particle and substrate surface and hence it causes a decrease in adhesion force. In the case of capillary force, the increase of surface roughness prevents the formation of a complete capillary meniscus at the particle-substrate surface contact point and hence weakens or prevents the capillary force formation.

In this work, the smaller particles of TC-1 (2-5 nm) have increased the surface roughness which in turn reduced the adhesion bond between dust particles and the substrates as further shown in Fig. 7. This particle size effect of $\mathrm{TiO}_{2}$ on the coating film efficiency has been reported earlier by Salvaggio et al. [24] when they reported on the increase of surface roughness of the coated films when $\mathrm{TiO}_{2}$ nanoparticle size was reduced from 31 to $20 \mathrm{~nm}$.

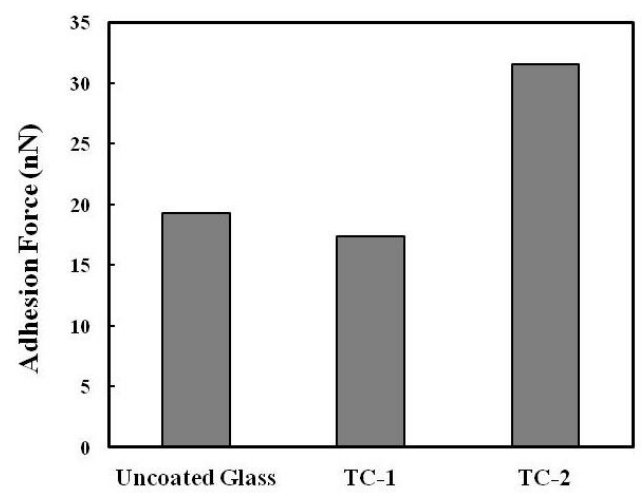

Fig. 7 The average adhesion forces measured between dust particles and coated (TC1 and TC-2) and uncoated substrates

The measured contact angles of the deposited films show medium hydrophilicity and the values are in agreement with what has been reported earlier for anatase $\mathrm{TiO}_{2}$ thin films deposited on glass substrates using different methods such electrospinning [25], liquid frame spray [26] and sol-gel dip coating [27]. Fig. 8 shows the contact angle over the coated (TC-1 and TC-2) and the uncoated samples. The water spread is an important factor for self-cleaning or for manual cleaning with water as an outside source. It is noticed that there is a negligible difference in the wettability of the two coating samples with slightly less contact angle of TC-1 compared with TC-2. This would have a direct effect on the strength of capillary bond as it is proportionally correlated with $\cos \theta$ as per eqn. (7) $[28,29]$ :

$$
\mathrm{F}_{\text {capillary }}=4 \pi \mathrm{R} \gamma \cos \theta
$$

where $\mathrm{R}$ is the particle redius, $\gamma$ is the surface tension, $\mathrm{z}$ is the separation distance between the particle and the substrate surface and $\theta$ is the contact angle.

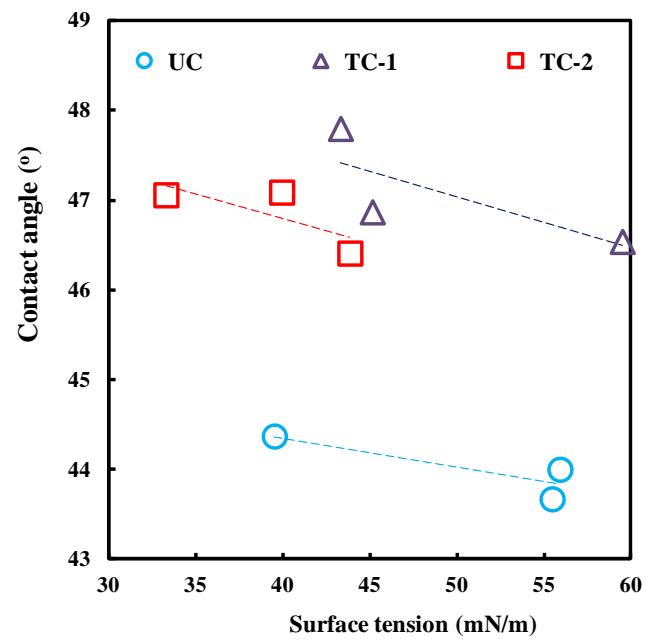

Fig. 8 The surface tension vs. contact angle of the coated (TC-1 and TC-2) and uncoated sample
The role of $\mathrm{TiO}_{2}$ thin films for self-cleaning application is effective; first through its photocatalytic activity which minimizes the affinity of dust deposition on surfaces by decomposing the organic matter and cleaning the surface, thus reducing the sticky material that builds up over time on which dust deposits and becomes harder to remove [30, 31]. The other role of $\mathrm{TiO}_{2}$ is by its hydrophilic and wettability properties which are suitable for desert humid region. Although $\mathrm{TiO}_{2}$ role as a self-cleaning coating has proved to be efficient to reduce dust deposition, it cannot be avoided that after considerable time of exposure to dust under humid dry conditions that washing the surfaces with water from time to time should take place. Nevertheless, the frequency of washing is much less when the surfaces are coated compared with the case of uncoated surfaces. Hence the hydrophilic properties should also prevail for a more efficient cleaning process.

\section{Conclusion}

In the present work, we reported on the characterization of two $\mathrm{TiO}_{2}$ thin films developed via adsorptive self-assembly method. The $\mathrm{TiO}_{2}$ nanocoalloids were synthesized via polyol method starting from two different Ti-precursor salts. TC- 1 coatings have reduced rate of dust deposition after soiling for 7 days compared with uncoated glass samples. The colloidal coating with particles size of $167 \mathrm{~nm}$ (TC-2) performed less efficient than the colloidal with much smaller particle of about $2.6 \mathrm{~nm}$ size (TC-1). The refractive index was less for TC-1 compared with TC-2 as well which is a critical property for the self-cleaning application of photovoltaic solar panels. Moreover, TC- 1 had higher surface roughness which weakened the adhesion bond between dust particles and the substrate surface.

\section{Acknowledgements}

We acknowledge financial support from Qatar Environment and Energy Research Institute (QEERI), at Hamad Bin Khalifa University-Qatar Foundation (Doha, Qatar). Authors would like to thank Dr. Tarik Rhadfi for the synthesis of the nanoparticles, Dr. Sergey Suslov for helping with obtaining TEM images and Dr. Amir Abdullah (QEERI) for providing the clean glass substrates.

\section{Author Contributions}

R.I. helped with $\mathrm{TiO}_{2}$ colloidal synthesis, performed the coating of the samples, optical microscopy, contact angle measurements, surface tension measurements, UV-Vis, analysis of data obtained and wrote the article. D.J. performed AFM for surface roughness of the films and the measurement of adhesion forces, S.M. obtained TEM images of $\mathrm{TiO}_{2}$ nanoparticles, A.S. performed ellipsometry measurements for film thickness and refractive index, W.S. obtained SEM images and K.K. provided technical advice for the project.

\section{Competing financial interests}

The authors declare no competing financial interests.

\section{References}

[1] Y. Li, X. Yu, Q. Yang, Fabrication of $\mathrm{TiO}_{2}$ nanotube thin films and their gas sensing properties, J. Sensors 402174 (2009) 1-19.

[2] R. Zhang, X. Ai, Y. Wan, Z. Liu, D. Zhang, S. Feng, Surface corrosion resistance in turning of titanium alloy, Int. J. Corros. 823172 (2015) 1-8.

[3] P. Srinivasu, S.P. Singh, A. Islam, L. Han, Novel approach for the synthesis of nanocrystalline anatase titania and their photovoltaic application, Adv. Optoelectron. 539382 (2011) 1-5.

[4] E. Shi, L. Zhang, Z. Li, P. Li, Y. Shang, Y. Jia, et al., $\mathrm{TiO}_{2}$-coated carbon nanotubesilicon solar cells with efficiency of 15\%, Sci. Rep. 2 (2012) 884.

[5] B. Xi, L. Kumar Verma, J. Li, C. Singh Bhatia, A. James Danner, H. Yang, et al., TiO 2 thin films prepared via adsorptive self-assembly for self-cleaning applications, ACS Appl. Mater. Interf. 4 (2012) 1093-1102.

[6] Y.C. Liu, Y.F. Lu, Y.Z. Zeng, C.H. Liao, J.C. Chung, T.Y. Wei, Nanostructured mesoporous titanium dioxide thin film prepared by sol-gel method for dyesensitized solar cell, Int. J. Photoenergy 619069 (2011) 1-9.

[7] Y.M. Abdulraheem, S. Ghoraishi, L. Arockia-Thai, S.K. Zachariah, M. Ghannam The effect of annealing on the structural andoptical properties of titanium dioxide films deposited by electron beam assisted PVD, Adv. Mater. Sci. Eng. 574738 (2013) 1-10.

[8] L.F. Da Silva, W. Avansi, M.L. Moreira, A. Mesquita, L.J.Q. Maia, J. Andrés, et al., Relationship between crystal shape, photoluminescence, and local structure in 
$\mathrm{SrTiO}_{3}$ synthesized by microwave-assisted hydrothermal method, J. Nanomater. 890397 (2012) 1-6.

[9] R.J. Isaifan, A. Samara, W. Suwaileh, D. Johnson, W. Yiming, A.A. Abdallah, et al., Improved self-cleaning properties of an efficient and easy to scale up $\mathrm{TiO}_{2}$ thin films prepared by adsorptive self-assembly, Sci. Rep. 7 (2017) 9466.

[10] R.J. Isaifan, S. Ntais, M. Couillard, E.A. Baranova, Size-dependent activity of $\mathrm{Pt} / \mathrm{yttria}$-stabilized zirconia catalyst for wireless electrooxidation of ethylene and carbon monoxide in oxygen free environment, J. Catal. 324 (2015) 32-40.

[11] R.J. Isaifan, M. Couillard, E.A. Baranova, Low temperature-high selectivity carbon monoxide methanation over yttria-stabilized zirconia-supported $\mathrm{Pt}$ nanoparticles, Int. J. Hyd. Energy 42 (2017) 13754-13762.

[12] D. Johnson, F. Galiano, S.A. Deowan, J. Hoinkis, A. Figoli, N. Hilal, Adhesion forces between humic acid functionalized colloidal probes and polymer membranes to assess fouling potential, J. Memb. Sci. 484 (2015) 35-46.

[13] D. Johnson, N. Hilal, W.R. Bowen, Basic principles of atomic force microscopy, atomic force microscopy in process engineering: An introduction to AFM for improved processes and product, in: At. Force Microsc. Process Eng., IChemE, UK, 2009.

[14] A. Hind, L. Chomette, The determination of thin film thickness using reflectance spectroscopy, Agilent Technologies, USA, 2003.

[15] M. Sreemany, S. Sen, A simple spectrophotometric method for determination of the optical constants and band gap energy of multiple layer $\mathrm{TiO}_{2}$ thin films, Mater. Chem. Phys. 83 (2004) 169-177.

[16] X.T. Zhang, O. Sato, M. Taguchi, Y. Einaga, T. Murakami, A. Fujishima, Selfcleaning particle coating with antireflection properties, Chem. Mater. 17 (2005) 696-700.

[17] C. Tuchinda, S. Srivannaboon, H.W. Lim, Photoprotection of window glass, automobile glass, and sunglasses, J. Am. Acad. DermatologyN54 (2006) 845854.

[18] S.S. Latthe, S. Liu, C. Terashima, K. Nakata, A. Fujishima, Transparent, adherent, and photocatalytic $\mathrm{SiO}_{2}-\mathrm{TiO}_{2}$ coatings on polycarbonate for self-cleaning applications, Coatings 4 (2014) 497-507.

[19] B. Yoldas, Investigations of porous oxides as an antireflective coating for glass surfaces, Appl. Opt. 19 (1980) 1425-1429.
[20] J. Katainen, M. Paajanen, E. Ahtola, V. Pore, J. Lahtinen, Adhesion as an interplay between particle size and surface roughness, Colloid Interf. Sci. 304 (2006) 524-529.

[21] P. Solar, O. Kylian, M. Vandrovcova, L. Bacakova, J. Hanus, J. Vyskocil, et al., Particles induced surface nanoroughness of titanium surface and its influence on adhesion of osteoblast-like MG-63 cells, Appl. Surf. Sci. 324 (2015) 99-105.

[22] Y.I. Rabinovich, J.J. Adler, M.S. Esayanur, A. Ata, R.K. Singh, B.M. Moudgil Capillary forces between surfaces with nanoscale roughness, Adv. Colloid Interf. Sci. 96 (2002) 213-230.

[23] H.R. Moutinho, C. Jiang, B. To, C. Perkins, M. Muller, L. Simpson, Adhesion mechanisms on solar glass : E ff ects of relative humidity, surface roughness and particle shape and size, Sol. Energy Mater. Sol. Cells 172 (2017) 145-153.

[24] M.G. Salvaggio, R. Passalacqua, S. Abate, G. Centi, Transparent nanostructured titania coatings with self- cleaning and antireflective properties for photovoltaic glass surfaces, Chem. Eng. Trans. 43 (2015) 745-750.

[25] V.A. Ganesh, A.S. Nair, H.K. Raut, T.M. Walsh, S. Ramakrishna, Electrospun SiO nanofibers as a template to fabricate a robust and transparent superamphiphobic coating, RSC Adv. 2 (2012) 2067-2072.

[26] J.A. Pimenoff, A.K. Hovinen, M.J. Rajala, Nanostructured coatings by liquid flame spraying, Thin Solid Films 517 (2009) 3057-3060.

[27] R. Fateh, A.A. Ismail, R. Dillert, D.W. Bahnemann, Highly active crystalline mesoporous $\mathrm{TiO}_{2}$ films coated onto polycarbonate substrates for self-cleaning applications, J. Phys. Chem. C 115 (2011) 10405-10411.

[28] P. Lambert, S. Regnier, Surface and contact forces models within the framework of microassembly, J. Micromech. 3 (2006) 123-157.

[29] R.A. Bowling, An analysis of particle adhesion on semiconductor surfaces, J. Electrochem. Soc. 157 (1985) 2208-2214.

[30] M. Yada, Y. Inoue, I. Noda, T. Morita, T. Torikai, T. Watari, et al., Antibacterial properties of titanate nanofiber thin films formed on a titanium plate, J. Nanomater. 476585 (2013) 1-10.

[31] M.M. Mahlambi, C.J. Ngila, B.B. Mamba, Recent developments in environmental photocatalytic degradation of organic pollutants: the case of titanium dioxide nanoparticles - a review, J. Nanomater. 790173 (2015) 1-29. 